ever increasing importance at the present day: the studies of repeated cerebral concussion are of special interest.

\author{
W. RITCHIE RUSSELL
}

CLINICAL PRACTICE AND PHYSIOLOGY OF ARTIFICIAL RESPIRATION By J. M. K. Spalding and A. Crampton Smith. (Pp. vii +144 , illustrated. 30s.) Oxford: Blackwell Scientific Publications Ltd. 1963.

It is sometimes asserted that scientific interest and therapeutic endeavour are incompatible. In fact, the development of a therapy is often the stimulus to new scientific exploration. The introduction of intermittent positive pressure respiration by Lassen and Ibsen in 1952 in order to cope with the overwhelming epidemic of poliomyelitis in Copenhagen illustrates this well, for it has initiated a great deal of research on the physiology of respiration and of the circulation in man.

The present excellent volume gives an account of the therapeutic and scientific work of the Respiratory Unit in Oxford. It sets forth with admirable clarity the practice of artificial respiration, omitting no medical, nursing, or physiotherapeutic detail and supporting it with excellent illustrations. It goes on to describe their researches into the physiology of artificial respiration and the effect this has on gaseous exchange and the circulation. This is not expressed in the current technical jargon, which is unintelligible to all but the initiated, but in simple English which can be understood by all. The special considerations relevant to the management of poliomyelitis, polyneuritis, and tetanus are discussed as well as those appertaining to such less common conditions as chest injury and status epilepticus. The apparatus required for this kind of work is listed and the names and addresses of the suppliers given. Indeed, the authors appear to have thought of everything for they round off with an explanation of the symbols and abbreviations used by pulmonary physiologists together with references and a good index.

It is in all a first-class monograph and will be indispensable, not only for those engaged in this type of work, but also for those who may be called upon to see a patient in whom respiratory failure may threaten and about whom they may have to advise.

STAGNANT ANOXIA AND CARBON MONOXIDE POISONING A Clinical and Electroencephalographic Study in Humans. By Nenad Bokonjic. Supplement No. 21 to Electroencephalography and Clinical Neurophysiology. (Pp. ix +102 ; 15 figures; 9 tables. 40s.) Amsterdam, London, and New York: Elsevier Publishing Company. 1963. This monograph concerns clinical and E.E.G. observations on 27 patients with stagnant anoxia (after hanging or cardiac arrest) and 47 patients with carbon monoxide poisoning admitted to hospital during 1948-58 in Copenhagen. Neurological and limited psychological and pathological findings are reported, and an effort has been made to assess the prognostic value of the E.E.G. after acute anoxia. There is much of interest from both clinical and E.E.G. aspects and a comparison of the two types of anoxia has been rewarding. However, there are the usual difficulties with retrospective studies, e.g., limitations in number and timing of E.E.G. recordings, and more comprehensive psychological and follow-up data would have been helpful. Such limitations are important in view of the author's conclusion that the E.E.G. has little practical value after acute anoxia.

PROCEEDINGS OF THE SECOND INTERNATIONAL CONGRESS ON MENTAL RETARDATION Part I. Organic Bases and Biochemical Aspects of Imbecility. Part II. Psychological and Sociological Problems in Imbecility. Edited by Otto Stur. (Pp. viii + 416; illustrated. Pt. I: S.Fr./DM. 70.-, pt. II: S.Fr./DM. 50.-. Pts I and II: S.Fr./DM. 100.-.) Basel and New York: S. Karger AG. 1963.

The papers contained in these two excellently produced volumes give a balanced survey of the wide field covered by present-day research into the problems of mental retardation. The organic, biochemical, psychological, sociological, and therapeutic aspects of the subject are well represented. The organizers of this conference had invited a number of speakers to give lectures on themes of their own choosing, so that there are several more substantial contributions than are usually found in conference records of this sort. It is to be hoped that these proceedings will find their way not only into medical libraries but also into the hospitals for the subnormal in Britain, where the stimulus of research activities is so seldom available.

TREDGOLD'S TEXTBOOK OF MENTAL DEFICIENCY, 10th ed.

By R. F. Tredgold and K. Soddy. (Pp. xii + 530; 21

plates. 60s.) London: Baillière, Tindall \& Cox Ltd. 1963.

This is the tenth edition of Tredgold's well-known textbook which appeared first in 1908. Eight contributors, all from University College Hospital, London, now cover the clinical, social administration, psychological, and biological aspects of mental deficiency. The presentation of the material is not always well balanced: very little space, for example, is devoted to the recent discoveries of cytogenetics by comparison with the long exposition of the controversial view that 'the psychoses of childhood are properly to be regarded as psychological deficiency diseases resulting in disorders of relationship formation'. Nonetheless, room is found in 530 pages for reference to most features of the subject and the book can serve as a useful introduction to an important and rapidly expanding branch of medicine.

DETERMINANTS OF INFANT BeHAVIOUR II Edited by B. M.

Foss. (Pp. xii + 248; 24 plates; 29 figures; 12 tables. 45s.) London: Methuen \& Co. Ltd. 1963.

This book consists of the proceedings of the second series of seminars on mother-infant interaction organized by the Tavistock Clinic. It is subdivided into three parts, dealing in turn with animal studies, human studies, and problems of method and theory. Intensive observation of a small number of subjects, monkey and human, form the basis of the reports; the discussions lean heavily on ethological and psycho-analytical theory. The conclusions are inevitably tentative and the symposium is best viewed as an early stage in the development of an important field of study. 
PARAPLEGIA The Official Journal of the International Medical Society of Paraplegia. Vol. 1, no. 1, May 1963. Edited by L. Guttman. (£1.) Edinburgh and London: E. \& S. Livingstone Ltd.

This new quarterly journal is very well produced and we wish it every success.

W. RITCHIE RUSSELL

PROCEEDINGS OF THE AUSTRALIAN ASSOCIATION OF NEUROLOGISTS Vol. 1, No. 1, May 1963. Edited by E. Graeme Robertson. (Pp. 74; illustrated). Published by the Australian Association of Neurologists.

Many will welcome this new venture under the editorship of Dr. Graeme Robertson. This first volume has been published at the expense of Ciba Limited, and as no price is mentioned presumably the way to get a copy is to write for a free issue to The Editor, 33 Collins Street, Melbourne, C.1, Victoria, Australia. If this is to grow into a more formidable journal, it will probably be necessary to widen the scope substantially beyond a report of the proceedings. However, we wish those concerned every success.

\section{SYMPOSIUM NEURORADIOLOGICUM (VII)}

The seventh Symposium Neuroradiologicum will be held in New York City at the Waldorf-Astoria Hotel from 20 to 25 September 1964.

In addition to essays on subjects of diagnostic and therapeutic neuroradiological interest, there will be a symposium on Radiation and the Nervous System. The latter will include essays on radiobiology, effects of radiation encountered in outer space, and the use of ultra-sound and radioisotopes in diagnosis and therapy.

The official languages of the Symposium will be English, French, German, and Spanish. Application forms may be obtained from the President, Dr. Juan M. Taveras, Neurological Institute, 710 West 168th Street, New York 32, New York.

The New York World's Fair will be in progress at the time of the Symposium.

\section{CORRECTIONS}

There are certain printing errors in the paragraphs from $Z$ the paper 'Nerve fibre size in the carpal tunnel syndrome' by P.L. Thomas and P. M. Fullerton (J. Neurol Neurosurg.

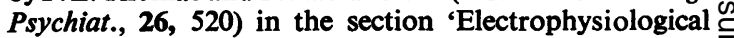
Studies'. The corrected paragraphs are as follows:-

In a normal subject, when the median nerve is stimulated at the wrist, the average latency to the $\frac{\hat{\rho}}{\partial}$ onset of the action potential recorded from the abductor pollicis brevis is $3.8 \mathrm{msec}$, with a range of 2.9 to 5 msec. (Thomas, 1960). The normal con- $\vec{F}$ duction velocity in the fastest motor nerve fibres to $\stackrel{\oplus}{\rightarrow}$ this muscle between the elbow and wrist is $57 \cdot 2 \mathrm{~m}$. $/ \mathrm{sec}$. with a range of 51.8 to $67.1 \mathrm{~m}$./sec. (Thomas, Sears, and Gilliatt, 1959).

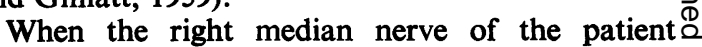
described here was studied, the shortest latency from the wrist was found to be $9 \mathrm{msec}$. (Fig. 1). Con- $\overrightarrow{0}$ duction velocity between the elbow and wrist for these fibres was $31.3 \mathrm{~m}$./sec. There was thus marked $\vec{\omega}$ slowing of conduction distal to the wrist; conduction velocity was also below the lower limit of the normal range in the forearm, as is commonly? found in patients with the carpal tunnel syndrome. with considerable slowing below the wrist (Thomass, 1960).

The values for the motor nerve fibres to the left abductor pollicis brevis were within the normintrange, the latency from the wrist being $3.5 \mathrm{msec}$. aed conduction velocity over the forearm $66.6 \mathrm{~m}$. $/ \mathrm{sec}$.

The authors of 'Studies in spina bifida' Part IV (J. Neurol. Neurosurg. Psychiat., 26, 545) wish to make an amefoment to the sixth line of the first paragraph of the? Discussion. It should read 'Two cases out of 15 operated' upon during the first week of life...'

\section{NOTICE TO CONTRIBUTORS}

Would intending authors kindly note that in future theyo are requested to put in their lists of references the full title of the paper quoted together with the numbers of the first and last pages. An example of how references should now be set out can be seen on the inside front? cover under the general instructions to contributors. 